This article is licensed under the Creative Commons Attribution-NonCommercial 4.0 International License (CC BY-NC) (http://www.karger.com/Services/OpenAccessLicense). Usage and distribution for commercial purposes requires written permission.

\title{
Comparison of Duodenal Mucosal Chromogranin-A Expression in Non-Alcoholic Fatty Pancreas Dyspeptic Patients with and without Endosonography-Diagnosed Early Chronic Pancreatitis: A Case Series Study
}

\author{
Chung-Tsui Huang $^{a} \quad$ Yao-Jen Liang ${ }^{b}$ \\ aGastroenterology and Hepatology Division, Internal Medicine Department, Far Eastern \\ Memorial Hospital, New Taipei City, Taiwan, ROC; ${ }^{b}$ Department of Life Science Institute of \\ Applied Science and Engineering, Fu Jen Catholic University, New Taipei City, Taiwan, \\ $\mathrm{ROC}$
}

\section{Keywords}

Chromogranin-A · Pancreatic fibrosis · Early chronic pancreatitis · Endosonography

\begin{abstract}
Nonalcoholic fatty pancreas (NAFP) is hypothetically related to progressive fibro-inflammation of the pancreas whose exocrine function is controlled by enteroendocrine cells (EEC). There is little evidence of pancreatic fibrosis in fatty pancreas and of whether there are quantitative differences for EEC. This study aimed to prove the coexistence of NAFP and pancreatic fibrosis or early chronic pancreatitis (ECP) using acoustic radiation force impulse (ARFI) and endosonography. Besides, the expression of duodenal mucosal chromogranin-A, a surrogate for EEC, was analyzed. Dyspeptic patients were surveyed the digestive clinic and received abdominal
\end{abstract}




\section{Case Reports in Gastroenterology}

Case Rep Gastroenterol 2019:13:102-112

DOI: $10.1159 / 000497777$

(c) 2019 The Author(s). Published by S. Karger AG, Base www.karger.com/crg

Huang and Liang: Comparison of Duodenal Mucosal Chromogranin-A Expression in NAFP Dyspeptic Patients with and without Endosonography-Diagnosed ECP

sonography, endosonography, and serology tests. Cases with organic causes of dyspepsia were excluded. Pancreatic fibrosis was defined as an ARFI value $\geq 1.3 \mathrm{~m} / \mathrm{s}$. ECP was defined by at least 2 scores of the Japan Pancreas Society endosonographic criteria. During endosonography, 4 biopsy samples of mucosa in the duodenal first part were obtained for analysis of chromogranin-A expression by Western blot. Mucosal biopsy was also performed at the gastric antrum for surveillance of Helicobacter pylori. Between January and June 2018, a total of 24 patients with NAFP were enrolled among 48 candidates and divided into 2 groups based on whether they had pancreatic fibrosis or not. In the pancreatic fibrosis group ( $n=11$, pancreatic ARFI: $1.76 \pm 0.34 \mathrm{~m} / \mathrm{s})$, there was a higher endosonographic criteria score (2.45 vs. $1.61, p=$ $0.002)$, increased expression of chromogranin-A $(p=0.001)$, and more severe fatty pancreas that was defined by pancreatic duct blurring on abdominal sonography ( $91 \mathrm{vs.} 46 \%, p=0.062$ ) as compared to the non-pancreatic fibrosis group ( $n=13$, pancreatic ARFI: $1.11 \pm 0.09 \mathrm{~m} / \mathrm{s}$ ). A total of 54 endosonographic abnormalities of ECP was present in these 24 patients in the head $(52 \%)$, body $(31 \%)$, and tail $(17 \%)$, an anatomic pattern similar to pancreatic adenocarcinoma. In conclusion, among dyspeptic patients with NAFP, the duodenal mucosa chromogranin-A showed increased expression in those with pancreatic fibrosis and endosonography-diagnosed ECP.

(C) 2019 The Author(s)

Published by S. Karger AG, Basel

\section{Introduction}

Fatty pancreas is a pathologic entity with a prevalence of approximately $10-16 \%$ [1-7]. Its association with endocrine disease-like diabetes mellitus or pancreatic cancer has been partially studied [4, 8-10]. However, there is less medical evidence of an association between fatty pancreas and pancreatic fibrosis or early chronic pancreatitis in the exocrine field.

Pancreatic fibrosis is an initial stage of chronic pancreatitis [11, 12]. Early chronic pancreatitis requires mechanistic definitions using combined factors for a diagnostic approach [13]. The first assessment includes risk factors using the conventional TIGAR-0 classification system [14]. In the toxic and metabolic category, nonalcoholic fatty pancreas is a pathologic entity hypothetically contributing to pancreatic fibro-inflammation and organic dysfunction $[1,8,15]$. Pancreatic exocrine dysfunction is an etiology for dyspepsia. Hence, dyspepsia can reasonably be attributed to nonalcoholic fatty pancreas with concurrent early chronic pancreatitis or pancreatic fibrosis [12].

The second approach concerns symptoms and events of acute pancreatitis. Dyspepsia is a common manifestation of pancreatic exocrine dysfunction and can be classified as epigastric pain or postprandial distress syndrome [16-18]. The confirmation of acute pancreatitis needs clinical, laboratory, and image data, but patients do not always undergo complete examinations. Hence, one recent international consensus comments that an acute pancreatitis event is not mandatory for the diagnosis of early chronic pancreatitis [13].

Image characterization is inevitable for early chronic pancreatitis. Endoscopic ultrasonography (EUS) is currently considered the most sensitive modality to detect subtle structural changes of the pancreas [19]. For pancreatic fibrosis, the correlation between endosonographic findings and pancreatic histology is approximately 70-80\% [20]. The major limitation of endosonography is operator-dependent variability of this technique. Shear wave 


\section{Case Reports in Gastroenterology}

Case Rep Gastroenterol 2019;13:102-112

DOI: $10.1159 / 000497777$

(c) 2019 The Author(s). Published by S. Karger AG, Base www.karger.com/crg

Huang and Liang: Comparison of Duodenal Mucosal Chromogranin-A Expression in

NAFP Dyspeptic Patients with and without Endosonography-Diagnosed ECP

elastography, such as acoustic radiation force impulse (ARFI), can provide a quantitative assessment of parenchymal fibrosis in chronic pancreatitis [21-26]. Hence, the combination of endosonography and elastography analysis is complementary in the evaluation of early chronic pancreatitis.

Enteroendocrine cells are specialized chemoreceptor cells located in the epithelium of the gastrointestinal tract and control pancreatic function by signaling secretory molecules in response to luminal contents [27]. Hypothetically, the expressions of enteroendocrine cells would be dynamically changed in the early stage of chronic pancreatitis when pancreatic exocrine dysfunction is presenting as dyspepsia. Chromogranin-A is a protein product of enteroendocrine cells and can be used as a surrogate for a quantitative analysis of enteroendocrine cells [28-30].

The aims of this study were (1) to prove the coexistence of nonalcoholic fatty pancreas with pancreatic fibrosis and early chronic pancreatitis and (2) to analyze the endosonographic characteristics of pancreatic fibrosis and the expression of chromogranin-A in duodenal mucosa.

\section{Materials and Methods}

\section{Patients and Procedures}

Patients with the chief complaint of recurrent dyspepsia were surveyed for this study at physician Huang's clinic at Far Eastern Memorial Hospital, New Taipei City, Taiwan. The enrolled cases received a transabdominal sonography, upper gastrointestinal EUS, and serologic tests. The inclusion criteria were (1) age 30 65 years old; (2) recurrent dyspepsia with a duration of over 1 week; and (3) presence of fatty pancreas on transabdominal sonography. The types of dyspepsia were epigastric pain syndrome or postprandial distress syndrome. The exclusion criteria consisted of (1) alarming symptoms or signs of the gastrointestinal tract, such as dysphagia, weight loss, and overt bleeding; (2) upper gastrointestinal endoscopy or transabdominal sonography performed within 6 months; (3) cirrhosis; (4) end-stage renal disease or uremia syndrome; (5) significant etiology of dyspepsia diagnosed during the study procedures; (6) cancer or suspected cancer; and (7) a history of pancreatic surgery.

During transabdominal sonography (Siemens Acuson S2000 Ultrasound System), the degree of fatty liver and fatty pancreas was recorded. The classification of fatty liver is as follows: (1) mild indicates higher echogenicity than the renal cortex; (2) moderate indicates hepatic vessel blurring; and (3) severe indicates obscured vision of hepatic vessels [31]. The diagnosis of fatty pancreas by transabdominal sonography is based on a stratification system with 3 classifications: (1) mild indicates echogenicity of the pancreatic body similar to the echogenicity of the retroperitoneal adipose tissue; (2) moderate indicates a blurred outline of the splenic vein or main pancreatic duct; and (3) severe indicates invisible splenic vein and deeper structures [32]. Besides, the ARFI value of the liver and pancreas was measured. The hepatic ARFI value was obtained by the mean value of 10 measurements in the hepatic right lobe. The pancreatic ARFI value was obtained by the mean value of 10 measurements in the pancreatic body parenchyma.

The serology examination included lipase, total bilirubin, triglycerides, total cholesterol, fasting glucose, and alanine transaminase. The upper gastrointestinal EUS was performed by 


\section{Case Reports in Gastroenterology}

Case Rep Gastroenterol 2019;13:102-112

DOI: $10.1159 / 000497777$

(c) 2019 The Author(s). Published by S. Karger AG, Base www.karger.com/crg

Huang and Liang: Comparison of Duodenal Mucosal Chromogranin-A Expression in NAFP Dyspeptic Patients with and without Endosonography-Diagnosed ECP

Chung-Tsui Huang (22 cases using GF-UE 260; 2 cases using UCT-260; Olympus Co., Tokyo, Japan). During the procedures, the mucosa of the upper gastrointestinal tract and pancreas were surveyed for organic lesions. Early chronic pancreatitis was evaluated using the EUS criteria provided by the Japan Pancreas Society (JPS) [33]. A biopsy of mucosa in the gastric antrum was performed twice for surveillance of Helicobacter pylori. A biopsy of mucosa in the first part of the duodenum was performed twice in the anterior wall and twice in the inferior wall. The sample of duodenal mucosa was stored in liquid nitrogen immediately. The duodenal mucosa sample was analyzed for chromogranin-A, cholecystokinin, and glucagon-like peptide-1 (GLP-1) by Western blot.

The diagnosis of pancreatic fibrosis was defined as pancreatic ARFI $\geq 1.3 \mathrm{~m} / \mathrm{s}$, and EUSdiagnosed early chronic pancreatitis was defined as $\geq 2$ abnormalities of JPS EUS criteria, exemplified in Figure 1. This study was approved by the Institutional Review Board of Far Eastern Memorial Hospital (FEMH 106142-F), and every participant signed an informed consent form.

\section{Western Blot Analysis}

The general procedure for the Western blot analysis was performed as follows. Tissue proteins were extracted by homogenization of tissue in protein extraction solution (iNtRON Biotechnology) and 1-mm zirconia beads followed by shock 5 times for 3 min and centrifugation at 13,000 rpm for $20 \mathrm{~min}$. The supernatants were collected, and protein concentrations were estimated using the BCA protein assay kit (Thermo). $30 \mu \mathrm{g}$ total protein was resolved in SDS-polyacrylamide gels on a Minigel apparatus and transferred to a PVDF membrane using a semidry transfer cell. The transblotted membrane was washed 3 times and blocked with PBST containing 5\% nonfat milk for $60 \mathrm{~min}$, and then the membrane was incubated with the appropriate primary antibody. The membrane was washed 3 times by PBST. Finally, the membrane was probed with horseradish peroxidase-conjugated secondary antibody and visualized by enhanced chemiluminescence. The density of the blot was further analyzed by densitometry using the TotalLab TL120v2009. The primary antibodies used were as follows: antichromogranin-A (Abcam, ab199014), CCK8 (Biorbyt, orb10260), GLP-1 (Biorbyt, orb10719), and $\beta$-actin (Santa Cruz, sc-47778). For analysis of protein expression, the case with the lowest pancreatic ARFI value in the non-early chronic pancreatitis group was defined as 1.0. The other cases were presented as a relative expression value for statistical calculation.

\section{Statistical Analysis}

All results were presented as means \pm standard deviations for continuous variables and as original numbers or percentages for categorical variables. For group data, $\chi^{2}$ and Pearson tests were used for categorical and continuous variables, respectively. An independent samples $t$ test was used for paired data. Data analyses were performed by using a standard software package (SPSS version 20.0, Chicago, IL, USA). A $p$ value of $<0.05$ was considered as statistically significant. 


\section{Case Reports in Gastroenterology}

Case Rep Gastroenterol 2019;13:102-112

DOI: $10.1159 / 000497777$

(c) 2019 The Author(s). Published by S. Karger AG, Base www.karger.com/crg

Huang and Liang: Comparison of Duodenal Mucosal Chromogranin-A Expression in

NAFP Dyspeptic Patients with and without Endosonography-Diagnosed ECP

\section{Results}

A total of 2,603 patients visited physician Huang's clinic between January and June 2018. Among the 2,603 patients, 305 patients presented with the chief complaint of dyspepsia. After medical historical evaluation, there were 48 candidates for the study, and eventually 24 patients were enrolled. The other 24 cases were excluded due to the following reasons: no fatty pancreas $(n=10)$, gallstone $(n=7)$, severe renal atrophy with uremia $(n=1)$, calcified chronic pancreatitis $(n=1)$, duodenal ulcer $(n=3)$, duodenal peptic stricture $(n=1)$, and echo-endoscope insertion failure $(n=1)$. The enrolled 24 study cases consisted of 10 men and 14 women.

The diagnosis of pancreatic fibrosis was defined by pancreatic ARFI $\geq 1.3 \mathrm{~m} / \mathrm{s}$. The 24 cases were further divided into 2 groups: pancreatic fibrotic $(n=11)$ and nonfibrotic groups $(n=13)$. Demographic characteristics are summarized in Table 1 . The age, gender ratio, fatty liver level, hepatic ARFI, infection rate with H. pylori, body mass index, and serologic data did not differ significantly between the 2 groups. The EUS criteria score for early chronic pancreatitis was significantly higher in the pancreatic fibrotic group ( 2.45 vs. $1.61, p=0.002)$. The proportion of fatty pancreas equal to or above level 2 was higher in the pancreatic fibrotic group ( 90.9 vs. $46.1 \%, p=0.062$ ).

There were a total of 48 scores of EUS criteria for early chronic pancreatitis in these 24 cases with corresponding 54 pancreatic anatomic locations because 1 abnormal EUS finding could coexist in different pancreatic locations, such as the head and body. The distribution of these factors showed a pattern similar to a bipolar distribution if cyst and dilated side branch were combined as one factor (Fig. 2). Besides, the distribution of these 54 anatomic locations showed a decreasing frequency in the order pancreatic head $(n=28,52 \%)$, body $(n=17$, $31 \%)$, and tail ( $n=9,17 \%)$, a pattern compatible with pancreatic duct adenocarcinoma (Fig. 3). The expression of duodenal mucosa chromogranin-A was significantly higher in the pancreatic fibrotic group than in the nonfibrotic group $(p=0.001)$. Otherwise, no difference was noted for cholecystokinin ( $p=0.719)$ and GLP-1 ( $p=0.338$ ) (Fig. 4).

\section{Discussion}

The major findings of this study included the following: (1) coexistence of nonalcoholic fatty pancreas, EUS-diagnosed early chronic pancreatitis, and pancreatic fibrosis; (2) the JPS EUS score of early chronic pancreatitis was higher in the pancreatic fibrotic group defined by a pancreatic ARFI value $\geq 1.3 \mathrm{~m} / \mathrm{s}$; (3) the distribution of EUS abnormalities for early chronic pancreatitis showed a decreasing frequency pattern from head to body to tail; and (4) the expression of duodenal mucosa chromogranin-A was increased in the pancreatic fibrotic group.

Fat infiltration of the pancreas will theoretically increase the risk of pancreatic fibrosis gradually. This hypothesis could be partially proved by evidence of pancreatic fibrosis and EUS findings of early chronic pancreatitis in fatty pancreas. Transabdominal sonography is limited due to clear image resolution when observing fatty pancreas, exemplified by the fact that a moderate fatty pancreas will make the main pancreatic duct blurred and obscured. ARFI can provide a noninvasive quantitative evaluation of pancreatic fibrosis but lacks morphologic information. EUS is a useful tool for the characterization of structural changes in the early stage of chronic pancreatitis. Therefore, a combined use of transabdominal sonography, ARFI, 


\section{Case Reports in Gastroenterology}

Case Rep Gastroenterol 2019;13:102-112

DOI: $10.1159 / 000497777$

(c) 2019 The Author(s). Published by S. Karger AG, Base www.karger.com/crg

Huang and Liang: Comparison of Duodenal Mucosal Chromogranin-A Expression in NAFP Dyspeptic Patients with and without Endosonography-Diagnosed ECP

and EUS is reasonable for the study of fatty pancreas and pancreatic fibrosis. However, the current study could merely prove the coexistence of fatty pancreas and early chronic pancreatitis in a cross-sectional method. The longitudinal follow-up of fatty pancreas evolution needs further research.

Pancreatic ARFI is feasible for assessing pancreatic parenchymal disease, including chronic pancreatitis [34]. A recent research analyzed the shear wave velocity of normal pancreas, asymptomatic fatty pancreas, and late-stage chronic pancreatitis with a resultant cutoff value of $1.3 \mathrm{~m} / \mathrm{s}$ for the former two entities and about $2.0 \mathrm{~m} / \mathrm{s}$ for the last one [35]. Another study aimed to analyze the normal shear wave velocity of normal pancreas, showing a cutoff value of $1.2 \pm 0.36 \mathrm{~m} / \mathrm{s}$ [36]. Hence, the interval of ARFI between 1.3 and $2.0 \mathrm{~m} / \mathrm{s}$ is probably the progressive range of early chronic pancreatitis. This study found that dyspeptic patients with a pancreatic ARFI value $\geq 1.3 \mathrm{~m} / \mathrm{s}$ had higher JPS EUS criteria scores for early chronic pancreatitis, and the mean score was $\geq 2$ in the study group. One Japanese study observed that a JPS EUS criteria score $\geq 2$ for early chronic pancreatitis is reasonable because these factors were early morphologic changes [16].

The endosonographic features of early chronic pancreatitis had 2 patterns meaningful for disease progression. Firstly, the 7 factors of JPS EUS criteria for early chronic pancreatitis showed a sequence corresponding to severity. Beginning with the last one, hyperechoic change of the main pancreatic duct margin represents the state of long-standing luminal increased pressure. Then, dilated side branches occur, partially forming focal tiny cysts. The stranding happens later when the side branch wall advances to thickening and fibrosis. Hyperechoic foci develop gradually within the lumen of side branches. Eventually, the mixture of stranding and hyperechoic foci leads to lobularity or honeycomb picture. This study showed a pattern similar to a bipolar distribution of endosonographic factors for early chronic pancreatitis if dilated side branch was combined with cyst. Secondly, the structural changes of early chronic pancreatitis were focal type with decreasing frequency from the pancreatic head to body to tail. This sequence is consistent with pancreatic duct adenocarcinoma, probably in that chronic pancreatitis is a risk factor for the former [10].

The enteroendocrine cell is a potential biomarker for dyspeptic patients with early chronic pancreatitis or pancreatic fibrosis because this cell controls pancreatic exocrine function. However, it is difficult to directly analyze mucosa cells. Hence, chromogranin-A can be a surrogate for the enteroendocrine cell, showing quantitative dynamic change in disease [28]. In this study, the cholecystokinin and GLP-1 did not differ significantly between the pancreatic fibrotic and nonfibrotic groups when analyzed in dyspeptic patients under a fasting status. However, the expression of chromogranin-A was increased in dyspeptic patients in the pancreatic fibrosis group under a fasting status. This phenomenon could be explained by the fact that the fibrotic pancreas requires more enteroendocrine cells in a fasting status to prepare the release of much more cytokine to stimulate pancreatic exocrine function for food digestion in the upper gastrointestinal lumen.

There were 4 major limitations of the current study. Firstly, this study was using ARFI to assess pancreatic fibrosis without histologic evidence. Secondly, the different expression of chromogranin-A was not correlated with the pancreatic exocrine test. Thirdly, the quantitative analysis of chromogranin-A in intestinal mucosa tissue is unavailable for commercial application currently. Finally, a well-designed double-blinded therapeutic trial using pancreatic enzymes replacement was lacking in this study. 
In conclusion, for adult patients with dyspepsia and nonalcoholic fatty pancreas, EUS can be considered for the assessment of early chronic pancreatitis in cases with a pancreatic ARFI $\geq 1.3 \mathrm{~m} / \mathrm{s}$. The chromogranin-A in duodenal mucosa showed increased expression in those cases with pancreatic fibrosis and EUS-diagnosed early chronic pancreatitis.

\section{Acknowledgement}

This study was supported by a grant for Chao-Yi Chen, a graduate student at the Department of Life Science Institute of Applied Science and Engineering of Fu Jen Catholic University, for his teaching and assistance with Western blot procedures.

\section{Statement of Ethics}

This study was approved by the Institutional Review Board of Far Eastern Memorial Hospital (FEMH 106142-F), and every participant signed an informed consent form.

\section{Disclosure Statement}

The authors declare that they have no conflicts of interest regarding the publication of this paper.

\section{References}

1 Tariq H, Nayudu S, Akella S, Glandt M, Chilimuri S. Non-Alcoholic Fatty Pancreatic Disease: A Review of Literature. Gastroenterol Res. 2016 Dec;9(6):87-91.

2 Zhou J, Li ML, Zhang DD, Lin HY, Dai XH, Sun XL, et al. The correlation between pancreatic steatosis and metabolic syndrome in a Chinese population. Pancreatology. 2016 Jul-Aug;16(4):578-83.

3 Wu WC, Wang CY. Association between non-alcoholic fatty pancreatic disease (NAFPD) and the metabolic syndrome: case-control retrospective study. Cardiovasc Diabetol. 2013 May;12(1):77.

4 Wang H, Maitra A, Wang H. Obesity, Intrapancreatic Fatty Infiltration, and Pancreatic Cancer. Clin Cancer Res. 2015 Aug;21(15):3369-71.

5 Lesmana CR, Pakasi LS, Inggriani S, Aidawati ML, Lesmana LA. Prevalence of Non-Alcoholic Fatty Pancreas Disease (NAFPD) and its risk factors among adult medical check-up patients in a private hospital: a large cross sectional study. BMC Gastroenterol. 2015 Dec;15(1):174.

6 Della Corte C, Mosca A, Majo F, Lucidi V, Panera N, Giglioni E, et al. Nonalcoholic fatty pancreas disease and Nonalcoholic fatty liver disease: more than ectopic fat. Clin Endocrinol (Oxf). 2015 Nov;83(5):656-62.

7 Sepe PS, Ohri A, Sanaka S, Berzin TM, Sekhon S, Bennett G, et al. A prospective evaluation of fatty pancreas by using EUS. Gastrointest Endosc. 2011 May;73(5):987-93.

8 Alempijevic T, Dragasevic S, Zec S, Popovic D, Milosavljevic T. Non-alcoholic fatty pancreas disease. Postgrad Med J. 2017 Apr;93(1098):226-30.

9 Ou HY, Wang CY, Yang YC, Chen MF, Chang CJ. The association between nonalcoholic fatty pancreas disease and diabetes. PLoS One. 2013 May;8(5):e62561.

10 Lesmana CR, Gani RA, Lesmana LA. Non-alcoholic fatty pancreas disease as a risk factor for pancreatic cancer based on endoscopic ultrasound examination among pancreatic cancer patients: A single-center experience. JGH Open. 2017 Dec;2(1):4-7. 
11 Kleeff J, Whitcomb DC, Shimosegawa T, Esposito I, Lerch MM, Gress T, et al. Chronic pancreatitis. Nat Rev Dis Primers. 2017 Sep;3:17060.

12 Lariño-Noia J, de la Iglesia D, Iglesias-García J, Macías F, Nieto L, Bastón I, et al. Morphological and functional changes of chronic pancreatitis in patients with dyspepsia: A prospective, observational, cross-sectional study. Pancreatology. 2018 Apr;18(3):280-5.

13 Whitcomb DC, Frulloni L, Garg P, Greer JB, Schneider A, Yadav D, et al. Chronic pancreatitis: an international draft consensus proposal for a new mechanistic definition. Pancreatology. 2016 Mar-Apr;16(2):218-24.

14 Etemad B, Whitcomb DC. Chronic pancreatitis: diagnosis, classification, and new genetic developments. Gastroenterology. $2001 \mathrm{Feb} ; 120(3): 682-707$.

15 Khoury T, Asombang AW, Berzin TM, Cohen J, Pleskow DK, Mizrahi M. The Clinical Implications of Fatty Pancreas: A Concise Review. Dig Dis Sci. 2017 Oct;62(10):2658-67.

16 Hashimoto S, Futagami S, Yamawaki H, Kaneko K, Kodaka Y, Wakabayashi M, et al. Epigastric pain syndrome accompanying pancreatic enzyme abnormalities was overlapped with early chronic pancreatitis using endosonography. J Clin Biochem Nutr. 2017 Sep;61(2):140-5.

17 Yang D, Forsmark CE. Chronic pancreatitis. Curr Opin Gastroenterol. 2017 Sep;33(5):396-403.

18 Yamawaki H, Futagami S, Kaneko K, Agawa S, Higuchi K, Murakami M, et al. Camostat Mesilate, Pancrelipase, and Rabeprazole Combination Therapy Improves Epigastric Pain in Early Chronic Pancreatitis and Functional Dyspepsia with Pancreatic Enzyme Abnormalities. Digestion. 2018 Nov, Epub ahead of print.

19 Iglesias-García J, Lariño-Noia J, Lindkvist B, Domínguez-Muñoz JE. Endoscopic ultrasound in the diagnosis of chronic pancreatitis. Rev Esp Enferm Dig. 2015 Apr;107(4):221-8.

20 Albashir S, Bronner MP, Parsi MA, Walsh RM, Stevens T. Endoscopic ultrasound, secretin endoscopic pancreatic function test, and histology: correlation in chronic pancreatitis. Am J Gastroenterol. 2010 Nov;105(11):2498-503.

21 Yashima Y, Sasahira N, Isayama H, Kogure H, Ikeda H, Hirano K, et al. Acoustic radiation force impulse elastography for noninvasive assessment of chronic pancreatitis. J Gastroenterol. 2012 Apr;47(4):427-32.

22 Kawada N, Tanaka S. Elastography for the pancreas: current status and future perspective. World J Gastroenterol. 2016 Apr;22(14):3712-24.

23 Kuwahara T, Hirooka Y, Kawashima H, Ohno E, Ishikawa T, Yamamura T, et al. Usefulness of shear wave elastography as a quantitative diagnosis of chronic pancreatitis. J Gastroenterol Hepatol. 2018 Mar;33(3):756-61.

24 He Y, Wang H, Li XP, Zheng JJ, Jin CX. Pancreatic Elastography From Acoustic Radiation Force Impulse Imaging for Evaluation of Diabetic Microangiopathy. AJR Am J Roentgenol. 2017 Oct;209(4):775-80.

25 Harada N, Ishizawa T, Inoue Y, Aoki T, Sakamoto Y, Hasegawa K, et al. Acoustic radiation force impulse imaging of the pancreas for estimation of pathologic fibrosis and risk of postoperative pancreatic fistula. Am Coll Surg. 2014 Nov;219(5):887-94.e5.

26 Bruno C, Minniti S, Bucci A, Pozzi Mucelli R. ARFI: from basic principles to clinical applications in diffuse chronic disease - a review. Insights Imaging. 2016 Oct;7(5):735-46.

27 Page AJ, Li H. Meal-Sensing Signaling Pathways in Functional Dyspepsia. Front Syst Neurosci. 2018 Apr;12:10.

28 Wölnerhanssen BK, Moran AW, Burdyga G, Meyer-Gerspach AC, Peterli R, Manz M, et al. Deregulation of transcription factors controlling intestinal epithelial cell differentiation; a predisposing factor for reduced enteroendocrine cell number in morbidly obese individuals. Sci Rep. 2017 Aug;7(1):8174.

29 Witte AB, Walker MM, Talley NJ, Aro P, Ronkainen J, Marrazzo V, et al. Decreased Number of Duodenal Endocrine Cells with Unaltered Serotonin-Containing Cells in Functional Dyspepsia. Am J Gastroenterol. 2016 Dec;111(12):1852-3.

30 Massironi S, Zilli A, Cavalcoli F, Conte D, Peracchi M. Chromogranin A and other enteroendocrine markers in inflammatory bowel disease. Neuropeptides. 2016 Aug;58:127-34.

31 Cengiz M, Sentürk S, Cetin B, Bayrak AH, Bilek SU. Sonographic assessment of fatty liver: intraobserver and interobserver variability. Int J Clin Exp Med. 2014 Dec;7(12):5453-60.

32 Smereczynski A, Kolaczyk K. Is a fatty pancreas a banal lesion? J Ultrason. 2016 Sep;16(66):273-280.

33 Shimosegawa T, Kataoka K, Kamisawa T, Miyakawa H, Ohara H, Ito T, et al. The revised Japanese clinical diagnostic criteria for chronic pancreatitis. J Gastroenterol. 2010 Jun;45(6):584-91.

34 Pozzi R, Parzanese I, Baccarin A, Giunta M, Conti CB, Cantù P, et al. Point shear-wave elastography in chronic pancreatitis: A promising tool for staging disease severity. Pancreatology. 2017 Nov - Dec;17(6):905-10.

35 Goertz RS, Schuderer J, Strobel D, Pfeifer L, Neurath MF, Wildner D. Acoustic radiation force impulse shear wave elastography (ARFI) of acute and chronic pancreatitis and pancreatic tumor. Eur J Radiol. 2016 Dec;85(12):2211-6. 


\section{Case Reports in Gastroenterology}

2019 The Author(s). Published by S. Karger AG, Basel www.karger.com/crg

Huang and Liang: Comparison of Duodenal Mucosal Chromogranin-A Expression in NAFP Dyspeptic Patients with and without Endosonography-Diagnosed ECP

36 Zaro R, Lupsor-Platon M, Cheviet A, Badea R. The pursuit of normal reference values of pancreas stiffness by using Acoustic Radiation Force Impulse (ARFI) elastography. Med Ultrason. 2016 Dec;18(4):425-30.
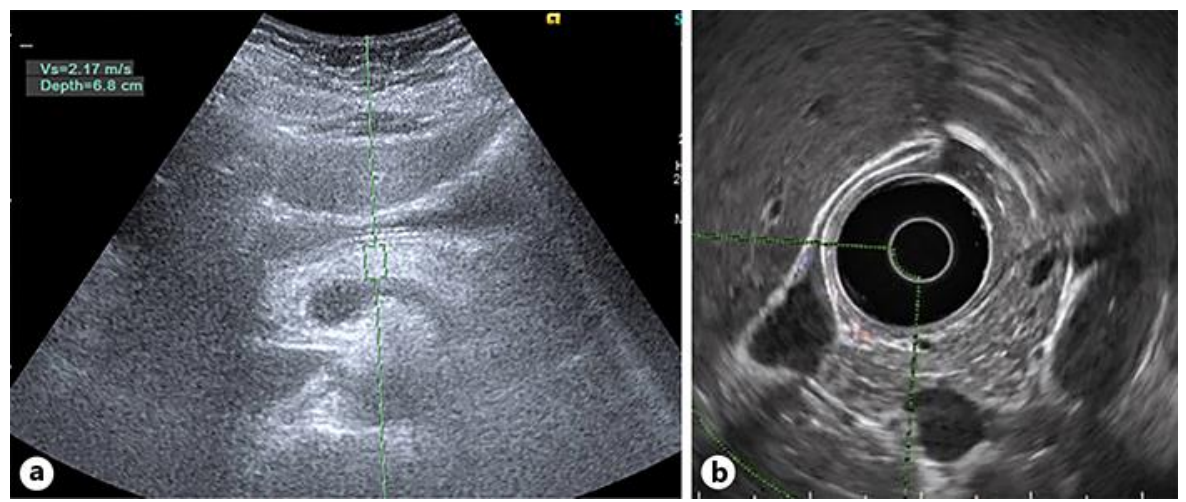

Fig. 1. a Example of ARFI measurement of fatty pancreas. b Example of stranding in the pancreatic head under EUS.

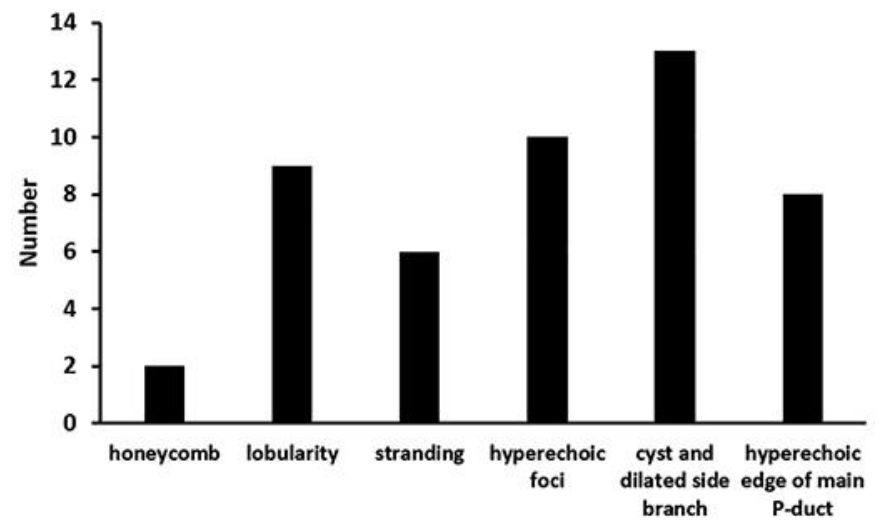

Fig. 2. Number of each endosonographic parameter for early chronic pancreatitis defined by the Japan Pancreas Society. The distribution of these factors showed a pattern similar to a bipolar distribution if cyst and dilated side branch were combined as one parameter. 


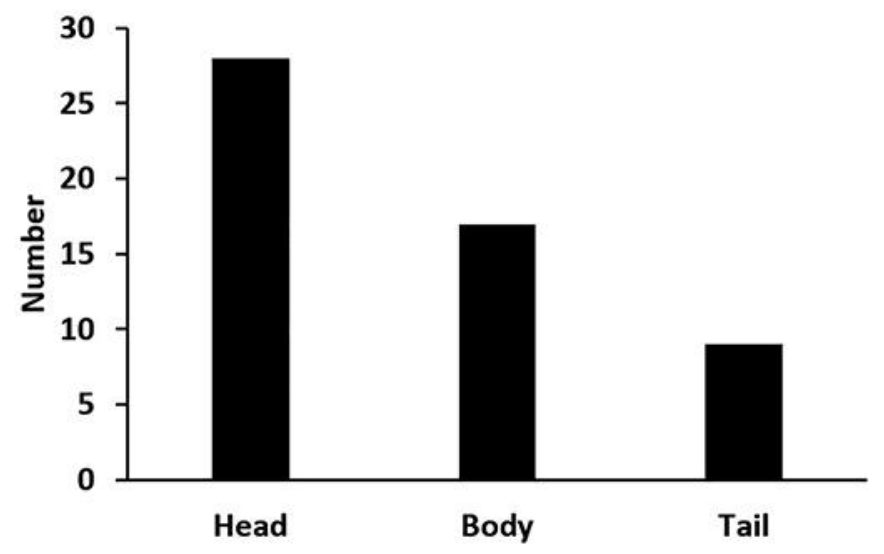

Fig. 3. Number of endosonographic abnormalities for early chronic pancreatitis in different pancreatic locations.

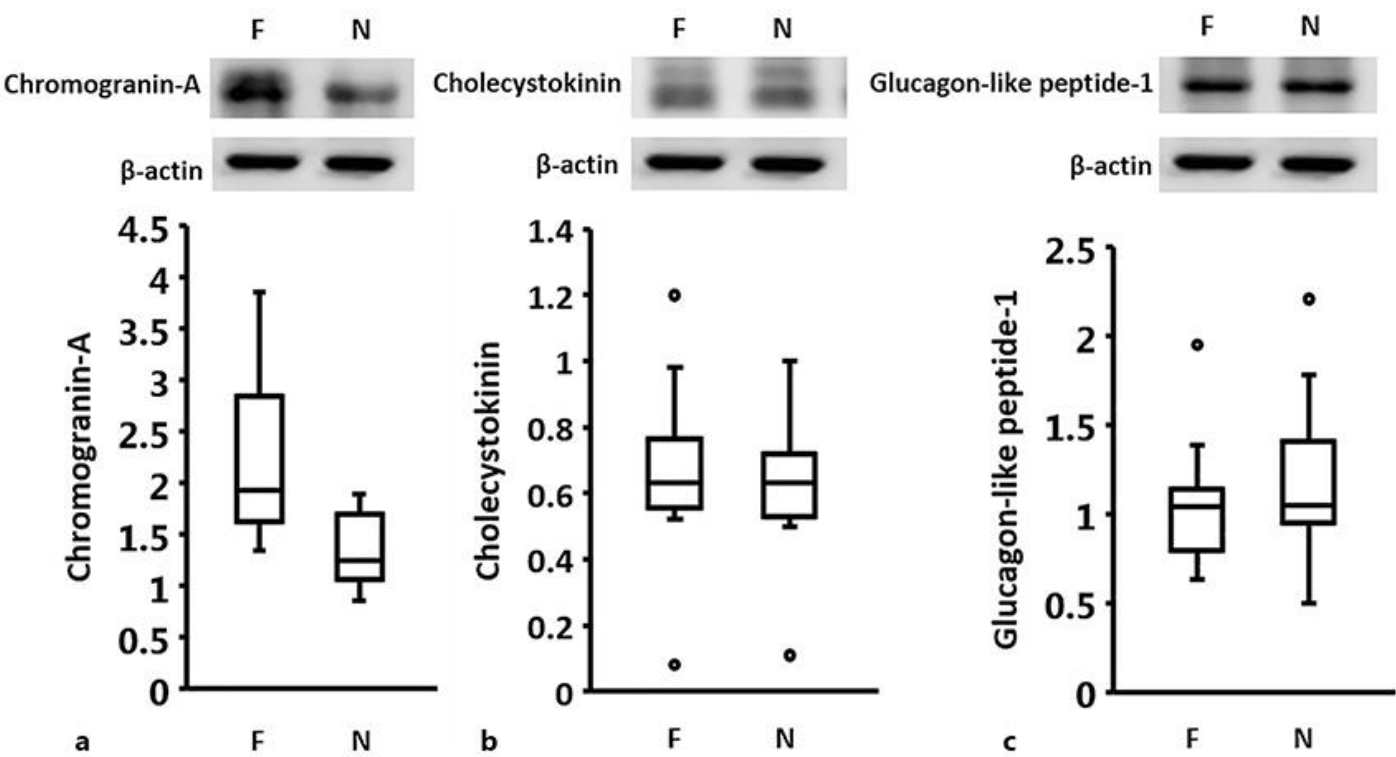

Fig. 4. Chromogranin-A (a), cholecystokinin (b), and glucagon-like peptide-1 (c) protein expression (Western blot) in duodenal mucosa biopsies in pancreatic fibrotic (F) and nonfibrotic (N) groups when dyspeptic patients were in a fasting state. An independent $t$ test analyzing differences of mean values using Levene's test for equality of variances was calculated. For Western blot, the upper panel represents each protein and the lower panel $\beta$-actin. For the box plot, the $y$ axis was a relative expression. The $p$ values in the comparison of expression between the 2 groups for chromogranin-A, cholecystokinin, and glucagon-like peptide- 1 were $0.001,0.719$, and 0.338 . 


\section{Case Reports in Gastroenterology}

\begin{tabular}{l|l}
\hline Case Rep Gastroenterol 2019;13:102-112 \\
\hline DOI: 10.1159/000497777 & $\begin{array}{l}\text { @ 2019 The Author(s). Published by S. Karger AG, Basel } \\
\text { www.karger.com/crg }\end{array}$ \\
\hline
\end{tabular}

Huang and Liang: Comparison of Duodenal Mucosal Chromogranin-A Expression in NAFP Dyspeptic Patients with and without Endosonography-Diagnosed ECP

Table 1. Demographic characteristics of the pancreatic fibrotic and nonfibrotic groups

\begin{tabular}{lllr}
\hline & $\begin{array}{l}\text { Pancreatic } \\
\text { fibrotic group } \\
\text { ARFI } \geq 1.3 \mathrm{~m} / \mathrm{s}) \\
(n=11)\end{array}$ & $\begin{array}{l}\text { Pancreatic } \\
\text { nonfibrotic group } \\
\text { (ARFI }<1.3 \mathrm{~m} / \mathrm{s}) \\
(n=13)\end{array}$ & $p$ value \\
& $52.18 \pm 9.59$ & $46.23 \pm 11.73$ & 0.193 \\
\hline Mean age \pm SD, years & $3 / 8$ & $8 / 5$ & 0.101 \\
Male/female & & & 0.258 \\
Dyspepsia type & 5 & 9 & \\
$\quad$ Epigastric pain syndrome & 6 & 4 & 0.266 \\
$\quad$ Postprandial distress syndrome & 54.6 & 76.9 & 0.459 \\
Dyspepsia course over 4 weeks, $\%$ & 23.9 & 22.6 & 0.178 \\
Mean body mass index & $7 / 4 / 0 / 0$ & $5 / 7 / 1 / 0$ & 0.958 \\
Fatty liver level, grade $0 / 1 / 2 / 3$ & 1.03 & 1.04 & 0.062 \\
Mean hepatic ARFI & $1 / 9 / 1$ & $7 / 5 / 1$ & 0.001 \\
Fatty pancreas level, grade $1 / 2 / 3$ & 1.76 & 1.12 & 0.002 \\
Mean pancreatic ARFI & & & \\
EUS scores of early chronic pancreatitis & $0 / 6 / 5$ & $6 / 6 / 1$ & 0.859 \\
$\quad$ 1/2/3 & 2.45 & 1.61 & 0.227 \\
$\quad$ Mean & 27.3 & 30.8 & 0.812 \\
Helicobacter pylori infection, $\%$ & $12 \sim 31$ & $8 \sim 38$ & 0.480 \\
ALT & $0.66 \pm 0.24$ & $0.63 \pm 0.25$ & 0.277 \\
Total bilirubin & $30.37 \pm 10.26$ & $36.27 \pm 21.23$ \\
Lipase & $95.27 \pm 17.65$ & $102.58 \pm 13.69$ & 0.816 \\
Fasting glucose & $186.18 \pm 31.74$ & $189.33 \pm 32.25$ & 0.216 \\
Total cholesterol & $105.18 \pm 41.33$ & $86.42 \pm 28.64$ & \\
Triglyceride & & & \\
\hline
\end{tabular}

